\title{
DISTAL RUPTURE OF THE TENDON OF BICEPS BRACHII
}

\author{
EVALUATION BY MRI AND THE RESULTS OF REPAIR
}

\author{
J. C. LE HUEC, M. MOINARD, F. LIQUOIS, B. ZIPOLI, \\ D. CHAUVEAUX, A. LE REBELLER
}

From Bordeaux Hospital, France

W $V^{e}$ report ten cases of rupture of the distal part of the tendon of biceps brachii in patients aged from 27 to 58 years. MRI allowed assessment of the degree of retraction of the tendon which was related to the integrity of the bicipital expansion. When the retraction exceeded $8 \mathrm{~cm}$ the expansion was always ruptured. When there was doubt, or in longstanding injury, MRI allowed the lesions to be defined.

Surgical repair was by reinsertion on the radial tuberosity at one or two fixation points in eight patients and reinsertion on the anterior brachial muscle in one. The other patient refused surgery. The MRI findings were confirmed at operation. Use of fixation points allowed minimal intervention, thereby reducing the risk of damaging the radial nerve. One year after operation, dynamometric evaluation of the strength of flexion and supination confirmed that the best results were obtained by reinsertion to the radial tuberosity.

J Bone Joint Surg [Br] 1996;78-B:767-70.

Received 4 March 1996; Accepted 17 April 1996

Ruptures of the distal part of the tendon of biceps brachii are rare (Hovelius and Josefsson 1977; Agins et al 1988), representing 3\% of biceps lesions (Kristensen 1991). Disinsertion of the tendon at the level of the bicipital tuberosity usually occurs (Kristensen 1991; Fitzgerald et al 1994). In 1941, Dobbie was the first to achieve a successful surgical repair. In view of the high frequency of late diagnosis of the lesion, two techniques have been proposed: fixation to the bicipital tuberosity (Gennari et al 1995) or reinsertion into the brachialis muscle (Dobbie 1941). Our aim was to

J. C. Le Huec, MD, Orthopaedic Surgeon

F. Liquois, MD, Orthopaedic Surgeon

B. Zipoli, MD, Orthopaedic Surgeon

D. Chauveaux, MD, Orthopaedic Surgeon

A. Le Rebeller, MD, Professor of Orthopaedics

M. Moinard, MD, Radiologist

Centre Hospitalier Universitaire, Pellegrin Tripode, 33076 Bordeaux Cedex, France.

Correspondence should be sent to Dr J. C. Le Huec.

(C)1996 British Editorial Society of Bone and Joint Surgery 0301-620X/96/51261 \$2.00 demonstrate the value of MRI in establishing a precise diagnosis and to assess the results of operation at a minimum follow-up of one year.

\section{PATIENTS AND METHODS}

Between January 1990 and December 1994, we treated ten male patients, aged between 27 and 58 years, with rupture of the distal part of the tendon of biceps brachii. The lesion had been caused by excessive strain while bending the arm to $90^{\circ}$. Eight patients were diagnosed early and treated before the sixth week, while the other two were seen six months after injury.

MRI evaluation. All patients were assessed by MRI at 1.5 Tesla with a surface probe. The patient was placed on his back, first with his arm along the body and hand in pronation and then with his hand in supination. T1 and T2 spin-echo axial and sagittal images were obtained. We did not use a paramagnetic contrast medium.

Operative technique. An incision is made on the anterior aspect of the elbow along the ulnar side of the tendon and continued along its radial side into the forearm. After opening the superficial aponeurosis, the biceps tendon is easily located in recent lesions. The bicipital expansion may be either partially or completely torn. The tendon is freed from adhesions with the superficial aponeurosis and its end sutured with non-absorbable thread. The primary course of the tendon is then located, with care not to damage the musculocutaneous nerve network. In recent injuries there is a distinguishable channel which can be easily followed to the bicipital tuberosity. Care is taken not to damage any of the terminal branches of the radial nerve which are situated just outside the channel.

The tuberosity is palpated by placing the forearm in maximum supination and displayed by inserting one or two Homan retractors. Two $2.9 \mathrm{~mm}$ holes are then drilled to create fixation points for the anchoring pins (Mitek super anchor 2.9, with 4 spikes; Mitek Surgical Products Inc, Westwood, Massachusetts; Fig. 1) (Barnes, Coleman and Gilpin 1993). Sutures are passed through the holes in the pins and attached to the distal part of the biceps tendon which is gradually pulled into position on the tuberosity with the elbow flexed to $90^{\circ}$. When tightening the sutures the forearm is maintained in a forcibly supinated position. The anchoring pins are always inserted in the innermost part of the tuberosity to gain maximum leverage (Fig. 2). 


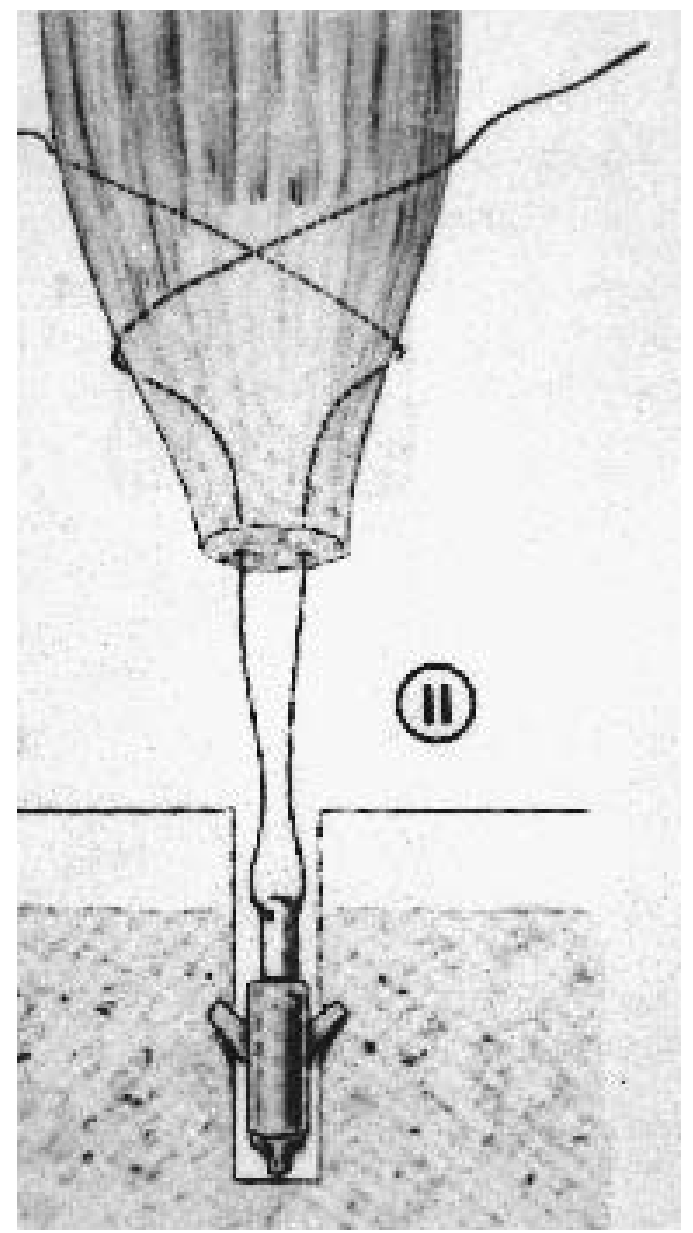

Fig. 1

Diagram of an anchor used for reinsertion of the tendon of biceps brachii.
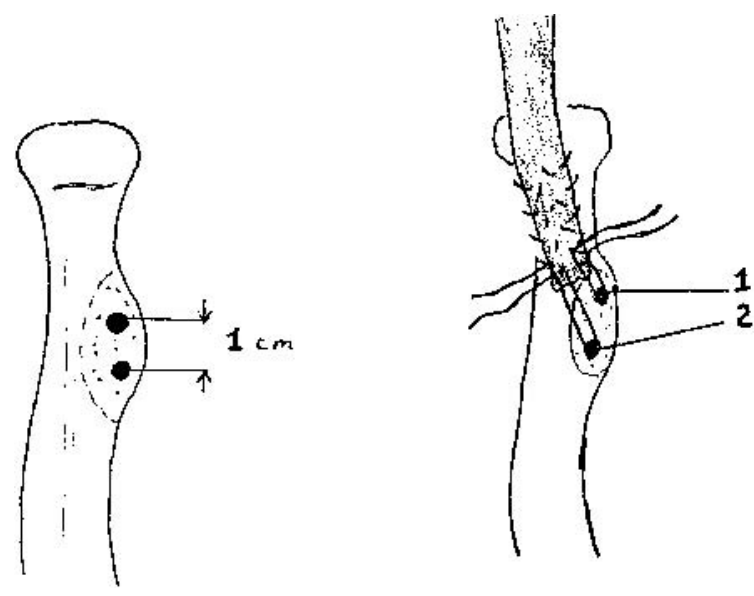

Fig. 2

Location of the two anchors for reinsertion of the tendon on the radial tuberosity.

Whenever possible, the expansion of the biceps is sutured. The aponeurosis and the skin are then closed over a Redon drain. After operation, the patient wears an articulated brace for six weeks, allowing movement only from $30^{\circ}$ to $140^{\circ}$ of flexion.
Assessment. Mobility, pain and the range of flexion and supination were measured one year after operation. Strength was evaluated by a Biodex dynamometer in absolute terms and as a percentage of the contralateral strength. It should be noted that Banker and Bierwagen (1985) had found that in normal subjects supination and flexion on the dominant side exceeded those on the opposite side by $27 \%$ and $15 \%$, respectively.

\section{RESULTS}

Preoperative MRI assessment and correlation at operation. Complete rupture of the tendon was diagnosed by its absence at the site of insertion on the radial tuberosity. When this occurred $\mathrm{T} 2$ sequences showed an empty tendon sheath filled with liquid. In recent lesions there was a hyperintense signal in the surrounding muscle indicating the presence of oedema and haematoma. If the lesion was longstanding there was a heterogeneous region with a liquid signal at the site of the tendon and muscle atrophy. The distance (Table I) between the distal end of the tendon and the tuberosity ranged from 5 to $14 \mathrm{~cm}$. At operation it was seen that when this distance was less than $8 \mathrm{~cm}$ with the forearm supine and extended the aponeurotic expansion of the tendon was not totally avulsed. A gap of greater than $8 \mathrm{~cm}$ on MRI indicated complete rupture (Figs 3 and 4).

Early results of surgical repair. We performed surgery in nine patients of whom eight had reinsertion on the radial tuberosity and the other attachment to the anterior part of the brachialis because the tendon had retracted too far. One patient refused surgery. There were no major complications. One patient had slight sensory disturbances in the distribution of the radial nerve which recovered by six weeks.

Follow-up at one year. All patients were able to flex the elbow to $160^{\circ}$ and had $90^{\circ}$ of supination. Six patients had no pain. Of the eight patients who had reinsertion four reported slight discomfort after repeated flexion and supination. Four had a forearm flexion-supination muscle strength of 40 to $45 \mathrm{~kg}$, two of 30 to $35 \mathrm{~kg}$ and two had a strength of 20 to $25 \mathrm{~kg}$. The patient with attachment to the anterior part of brachialis had a strength of $15 \mathrm{~kg}$, and the untreated patient $12 \mathrm{~kg}$. After reinsertion all eight patients had a loss of power of $11 \%$ compared with the other arm. The patient with the attachment to brachialis had a loss of $50 \%$. Radiography in two patients showed slight calcification of the distal end of the tendon around the bicipital tuberosity.

\section{DISCUSSION}

Avulsion of the distal attachment of biceps brachii has been reported rarely. The diagnosis is often delayed because, although the power of supination is diminished, flexion is only slightly affected.

MRI assessment allows the lesions to be clearly defined and has been used to evaluate painful degenerative lesions before rupture occurs (Falchook et al 1994; Fitzgerald et al 1994). 
Table I. Details of ten patients with distal rupture of the tendon of biceps brachii all on the dominant side

\begin{tabular}{|c|c|c|c|c|c|c|c|c|c|c|c|}
\hline Case & Sex & $\begin{array}{l}\text { Age } \\
(\mathbf{y r})\end{array}$ & Cause & Delay & Ultrasound & MRI & Lesion* & $\begin{array}{l}\text { Retraction } \\
\text { on MRI } \dagger \\
(\mathrm{cm})\end{array}$ & $\begin{array}{l}\text { Operative } \\
\text { treatment }\end{array}$ & Complications & $\begin{array}{l}\text { Flexion/ } \\
\text { supination } \\
\text { force(kg) }\end{array}$ \\
\hline 1 & M & 27 & Sport & 2 wks & Yes & Yes & + & 14 & Anchor & None & 45 \\
\hline 2 & M & 52 & Sport & $6 \mathrm{wks}$ & & Yes & + & 10 & Anchor & None & 34 \\
\hline 3 & M & 40 & Work & 2 dys & Yes & Yes & - & 6 & Anchor & None & 43 \\
\hline 4 & M & 43 & Work & 2 wks & & Yes & + & 11 & Anchor & None & 27 \\
\hline 5 & M & 47 & Sport & 3 wks & Yes & Yes & - & 5 & Anchor & None & 42 \\
\hline 6 & M & 55 & Work & $8 \mathrm{mths}$ & & Yes & + & 12 & $\mathrm{BA} \neq$ & None & 15 \\
\hline 7 & M & 58 & Work & $6 \mathrm{mths}$ & Yes & Yes & & 11 & & None & 12 \\
\hline 8 & M & 41 & Sport & 2 wks & Yes & Yes & + & 9 & Anchor & $\begin{array}{l}\text { Radial nerve } \\
\text { sensory } \\
\text { disturbance }\end{array}$ & 41 \\
\hline 9 & M & 39 & Work & 3 wks & & Yes & - & 5 & Anchor & None & 33 \\
\hline 10 & M & 57 & Work & $1 \mathrm{wk}$ & Yes & Yes & + & 11 & Anchor & None & 28 \\
\hline
\end{tabular}

$*+=$ rupture of the biceps brachii and of the expansion; - = rupture of the biceps brachii without the expansion

$\dagger$ distance between the distal part of biceps brachii and the radial tuberosity

$\ddagger$ reinsertion on the brachialis anterior

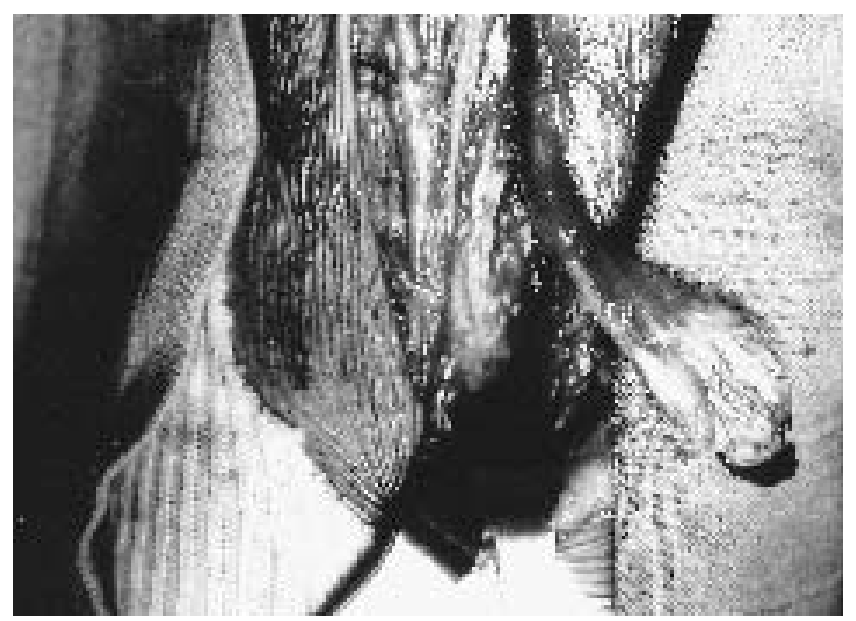

Fig. 3

Complete rupture of the distal part of the tendon of biceps brachii.

When the clinical diagnosis is uncertain, MRI can confirm the diagnosis, especially when the aponeurotic expansion of the tendon is not ruptured and retraction is less than $8 \mathrm{~cm}$. In longstanding ruptures, there may be a mass in the fold of the elbow which could lead to the false diagnosis of a tumour. MRI avoids this by demonstrating the absence of insertion of the tendon. In partial ruptures MRI may preclude the need for operation by demonstrating oedema and haematoma in the muscles but without rupture of the tendon (Fitzgerald et al 1994). None of our patients had a partial rupture, but the aponeurotic extension of the tendon was still intact in three of our cases. Morrey et al (1985) have pointed out that the integrity of this expansion affects retraction. Preoperative MRI confirms this by allowing evaluation of the distance between the distal end of the tendon and the bicipital tuberosity.

Since the insertion of the biceps at the radial tuberosity plays an important role in supination of the forearm, it is essential to fix the tendon to the tuberosity rather than to

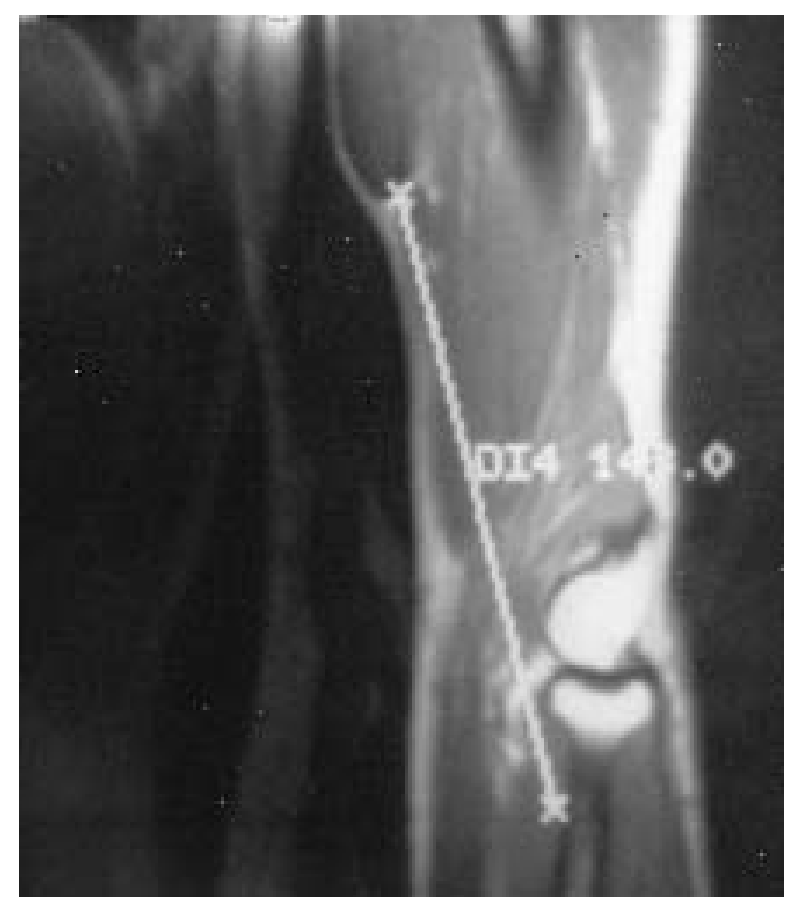

Fig. 4

MRI showing the distance between the distal part of the tendon and the radial tuberosity $(14 \mathrm{~cm}=$ total rupture $)$.

the tendon of the anterior part of brachialis (Catonné et al 1995). Wagner (1956) suggested using fascia lata as a tendon graft but the operation was difficult to perform and needed two incisions. In recent injuries direct fixation to the radial tuberosity is a simple, precise and, in principle, riskfree procedure (Gennari et al 1995). A minimal approach with anchor points avoids the risk of damaging the radial nerve and causes minimal damage to bone and soft tissue, unlike the method of Boyd and Anderson (1961) which requires a longer tendon. 
Like Gennari et al (1995), who used a similar technique, we observed only one transitory lesion of the radial nerve with sensory disturbance. Meherin and Kilgore (1960) reported partial damage to the radial nerve in three patients from a total of six biceps reinsertions, but they used a much wider approach involving large retractors.

Our observation that reinsertion on the anterior aspect of brachialis led to loss of $50 \%$ of the power of supination compared with attachment to the tuberosity has been noted previously (Baker and Bierwagen 1985; Morrey et al 1985; Catonné et al 1995; Gennari et al 1995).

No benefits in any form have been received or will be received from a commercial party related directly or indirectly to the subject of this article.

\section{REFERENCES}

Agins HJ, Chess JL, Hoekstra DV, Teitge RA. Rupture of the distal insertion of the biceps brachii tendon. Clin Orthop 1988;234:34-8.

Baker BE, Bierwagen D. Rupture of the distal tendon of biceps brachii: operative versus non-operative treatment. J Bone Joint Surg [Am] 1985;67-A:414-7.

Barnes SJ, Coleman SG, Gilpin D. Repair of avulsed insertion of biceps: a new technique in four cases. J Bone Joint Surg [Br] 1993;75-B: 938-9.
Boyd MM, Anderson LD. A method for reinsertion of the distal biceps brachii tendon. J Bone Joint Surg [Am] 1961;43-A:1041-3.

Catonné Y, Delatrre O, Pascal-Mousselard H, et al. Rupture of the distal tendon of the biceps brachialis: à propos of 43 cases. Rev Chir Orthop Reparatrice Appar Mot 1995;81:163-72.

Dobbie RP. Avulsion of the lower biceps brachii tendon: analysis of fiftyone previously unreported cases. Am J Surg 1941;51:662-83.

Falchook FS, Zlatkin MB, Erbacher GE, et al. Rupture of the distal biceps tendon: evaluation with MR imaging. Radiology 1994;190: 659-63.

Fitzgerald SW, Curry DR, Erickson SJ, Quinn SF, Friedman F. Distal biceps tendon injury: MR imaging diagnosis. Radiology 1994; 191:203-6.

Gennari JN, Merrot T, Ripoll B, Bergoin M. Surgical treatment of the rupture of the inferior tendon of the biceps. Rev Chir Orthop 1995; 81:173-7.

Hovelius L, Josefsson G. Rupture of the distal biceps tendon: report of five cases. Acta Orthop Scand 1977;48:280-2.

Kristensen PW. Distal avulsion of the biceps brachii tendon. Injury 1991;22:151-2.

Meherin JM, Kilgore ES. The treatment of ruptures of the distal biceps brachii tendon. Am J Surg 1960;99:636-40.

Morrey BF, Asken L, Kai Nan AN, Dobyns JH. Rupture of the distal tendon of biceps brachii: a biomechanical study. J Bone Joint Surg [Am] 1985;67:418-20.

Wagner CJ. Disinsertion of the biceps brachii. Am J Surg 1956;91: 647-50. 